\title{
A percepção de estudantes da área da saúde sobre o trabalho interdisciplinar: experiência no projeto de extensão Sorriso de Plantão
}

Débora de Cerqueira Santana; Maria Rosa da Silva²

Resumo: O objetivo deste estudo foi descrever a percepção dos estudantes da área da saúde sobre o trabalho interdisciplinar, no decorrer da formação e experiência no Projeto de Extensão Universitária Sorriso de Plantão. O projeto, criado em 2002, na Universidade Federal de Alagoas, atualmente em parceria com a Universidade Estadual de Ciências da Saúde de Alagoas, permite aos estudantes de diversos cursos da área da saúde atuarem em equipe interdisciplinar desde o início da formação profissional. O estudo exploratório, de abordagem qualitativa, entrevistou doze estudantes com mais de um ano de experiência no projeto para a produção dos dados. Os dados foram analisados com a técnica de Análise de Conteúdo de Bardin na modalidade temática. As categorias temáticas delineadas foram: entendimento sobre interdisciplinaridade durante a formação profissional em saúde; potencialidades e desafios do trabalho interdisciplinar: tarefa (im)possível? Com base nestas categorias, consideramos que as atividades extensionistas durante a formação podem superar visões mecanicistas e fragmentadoras do cuidado em saúde, dando lugar a uma formação holística, capaz de gerar novas respostas às demandas contemporâneas, ampliando o potencial de cada futuro profissional e as possibilidades dos coletivos trabalharem interdisciplinarmente.

Palavras-chave: Ensino Superior; Formação em Saúde; Saúde Pública

Health students' perceptions on interdisciplinary work: experience at the outreach project smile on duty

Abstract: The purpose of this study is to report on health students' perceptions on interdisciplinary work throughout education and experience at the University Outreach Project Smile on Duty. This project, created in 2002 at the Universidade Federal de Alagoas, now in partnership with Universidade Estadual de Ciências da Saúde de Alagoas, allows health students from multiple subfields to act in multidisciplinary teams from the beginning of their academic education. For this study, 12 students with more than 1 year of experience in the project were interviewed from an exploratory, qualitative approach. Bardin's techniques for content was used to study the data. The thematic categories proposed were: understanding on interdisciplinarity during academic education in health sciences; potential and challenges of interdisciplinary work: (im)possible task? Based on these categories, we believe that outreach activities during academic education may help students to overcome fragmented and overly technical views about health work, capable of generating new responses to contemporary demands, promoting their potential to work collectively and answer to the current demands of interdisciplinary healthcare.

Keywords: Higher Education; Health Training; Public Health
Originais recebidos em

25 de fevereiro de 2019

Aceito para publicação em

04 de março de 2020

1

Terapeuta Ocupacional, Especialista em Saúde da Família pelo Programa de Residência Multiprofissional em Saúde da Família da Universidade Estadual de Ciências da Saúde de Alagoas. Maceió, Alagoas, Brasil.

Rua Dr. Jorge de Lima, 113 Trapiche da Barra, Maceió - AL, 57010-300.

deborahsantana.to@gmail.com 2 Enfermeira, Mestra em Ensino na Saúde, Professora Auxiliar do Núcleo de Saúde Materno Infantil e do Adolescente da Universidade Estadual de Ciências da Saúde de Alagoas. Maceió, Alagoas, Brasil. 


\section{Introdução}

A implementação do Sistema Único de Saúde (SUS) no Brasil revelou um novo paradigma de saúde no país, com a busca por modelos de atenção que valorizem a integralidade, o cuidado humanizado e a promoção da saúde. No entanto, para efetivação do SUS são necessárias estratégias que contribuam para a reordenação da formação brasileira em saúde, rompendo com a persistente estrutura fragmentada do ensino, e incluindo fatores essenciais como o trabalho em equipe e a interdisciplinaridade (Gonzalez \&Almeida, 2010).

O primeiro passo para compreender o conceito de interdisciplinaridade, corroborando com Fazenda (2008), se refere ao abandono de posições acadêmicas prepotentes e unidirecionais, que restringem uma nova maneira de enxergar e lidar com o conhecimento. Desse modo, a interdisciplinaridade pode ser entendida como "um trabalho em comum tendo em vista a interação das disciplinas científicas, de seus conceitos e diretrizes, de suas metodologias, de seus procedimentos, de seus dados e da organização de seu ensino" (Fazenda, 2011, p.34).

Por outro lado, historicamente, a formação dos profissionais de saúde é marcada por uma tendência ao trabalho isolado, frente à competição entre as distintas profissões, e distante de uma comunicação e colaboração efetiva entre as diferentes categorias profissionais. Assim, buscando superar esse cenário, e extrapolando a lógica tradicional do ensino em saúde para um fundamento interprofissional, avanços importantes surgem no contexto de formação e educação em saúde, no qual é possível destacar a aprovação da Lei de Diretrizes e Bases da Educação (LDB), Lei n. ${ }^{\circ} 9.394$ (BRASIL, 1996) e, ainda em âmbito federal, no ano de 2002, o estabelecimento das Diretrizes Curriculares Nacionais (DCN), pelo Conselho Nacional de Educação.

A LDB estabelece novas perspectivas para formação em nível superior, salientando a importância de maior flexibilidade na organização dos cursos de graduação em saúde. De acordo com Bazzo (2012), para que seja possível estabelecer conexões entre todas as áreas e, consequentemente, alcançar o trabalho interdisciplinar efetivo na equipe de saúde, torna-se necessário que cada profissão ultrapasse a sua própria área de formação e competência, entendendo a interprofissionalidade como a prática profissional da interdisciplinaridade nos serviços de saúde.

Nessa perspectiva, faz-se necessário refletir sobre a importância da interação entre estudantes de diferentes cursos na área da saúde desde o início da graduação profissional. Gattás (2005) destaca que a universidade, como formadora de recursos humanos para suprir as necessidades da sociedade, tem papel relevante na formação de profissionais da área da saúde, salientando que o exercício da interdisciplinaridade nas Instituições de Ensino Superior (IES) amplia as possibilidades de uma formação mais crítica e articulada às reais necessidades da população, com ênfase na integralidade do cuidado.

Outro aspecto importante a ser mencionado refere-se à Extensão Universitária, área fortemente caracterizada pela diversidade de conteúdos que envolvem os diferentes campos do conhecimento e que apresenta potente suporte teórico-acadêmico na perspectiva interdisciplinar. Del-Masso et al. (2017) destacam que a interdisciplinaridade fortalece as ações extensionistas favorecendo o estudo, a análise, a execução e a mudança de conteúdo, a partir de diversas áreas do conhecimento entrelaçadas entre si, superando noções estáticas e fragmentadas do aprendizado.

Por meio da relação entre ensino e extensão, estendem-se as relações entre os universitários de diferentes cursos, permitindo uma ampliação à perspectiva do estudante, bem como o contato com problemáticas contemporâneas, proporcionando enriquecimento da experiência discente tanto no nível teóricometodológico quanto de sua humanização (Oliveira \& Goulart, 2015). 
Partindo desse pressuposto, surge o questionamento sobre os impactos que a experiência em atividades de extensão universitária pode proporcionar aos estudantes da área da saúde para o desenvolvimento e fortalecimento do trabalho interdisciplinar durante a formação profissional. Nessa visão, destacamos o Projeto de Extensão Sorriso de Plantão, da Universidade Federal de Alagoas (UFAL), em parceria com a Pró-Reitoria de Extensão da Universidade Estadual de Ciências da Saúde de Alagoas (UNCISAL).

O Projeto de Extensão Universitária Sorriso de Plantão foi criado em 2002, por uma estudante de medicina da UFAL, inspirada nas ideias dos palhaços doutores de São Paulo. O projeto tem por objetivo amenizar a dor de crianças, adultos enfermos, e seus acompanhantes, nas instalações de seis hospitais públicos do município de Maceió.

Ao longo dos anos, o Projeto Sorriso de Plantão sofreu alterações em sua estrutura e, atualmente, a participação no projeto é permitida para universitários de todas as áreas do conhecimento, desde o início da graduação profissional. Por seu caráter interdisciplinar, o Sorriso de Plantão prioriza que as atividades desenvolvidas no projeto ocorram de forma articulada entre os integrantes de diferentes categorias profissionais. Dessa forma, cada equipe é dividida estrategicamente para que os estudantes possam dialogar, trocar experiências e saberes, resolver problemas e, consequentemente, aprender juntos.

É necessário ressaltar que a aquisição de conhecimentos, habilidades, competências e valores dependem de um ensino que faça a ponte entre a teoria e a prática, ligando ciência e trabalho. Nesse sentido, a formação em saúde precisa ser entendida e trabalhada de forma interdisciplinar, tendo no discente um agente ativo. $O$ estudante precisa ser comprometido, responsável, apto a planejar ações em equipe, assumir responsabilidades, tomar decisões diante dos fatos e interagir em seu meio (Peleias et al., 2010).

Considerando a necessidade de discutir a importância da interdisciplinaridade durante a graduação profissional em saúde, essa pesquisa tem por objetivo descrever a percepção dos estudantes da área da saúde sobre o trabalho interdisciplinar no decorrer da formação e experiência no Projeto de Extensão Sorriso de Plantão.

\section{Procedimentos Metodológicos}

Para viabilizar o estudo, a pesquisa foi submetida à apreciação do Comitê de Ética em Pesquisa e aprovada em 17 de abril de 2018 sob o n CAEE 83953318.8.0000.5011.

Trata-se de um estudo exploratório, de abordagem qualitativa. Para Minayo (2010b), a pesquisa qualitativa responde a questões muito particulares, pois se preocupa com um nível de realidade que não pode ser quantificado, possibilitando um profundo e rico entendimento do contexto pesquisado.

O estudo foi desenvolvido em uma Instituição de Ensino Superior (IES) pública do município de Maceió, sendo escolhido como cenário para pesquisa por sediar as reuniões gerais do Projeto de Extensão Sorriso de Plantão. Participaram da pesquisa estudantes dos cursos de graduação da área da saúde, de instituições públicas e privadas, sendo excluídos os que tivessem menos de um ano de experiência no projeto.

Os estudantes foram informados da realização da pesquisa e convidados a participar do estudo por meio de contato telefônico, totalizando doze integrantes que se adequaram aos critérios de inclusão e exclusão estabelecidos. Foi agendado o melhor dia e horário para realização da entrevista, de forma individual, com aqueles que indicaram interesse, inclusive sendo sugerido que as entrevistas ocorressem após as reuniões do Projeto de Extensão Sorriso de Plantão. Os participantes da pesquisa foram esclarecidos quanto aos objetivos e procedimentos do estudo, e em seguida foi lido e assinado o Termo de Consentimento Livre Esclarecido TCLE. 
Como instrumento metodológico para a produção dos dados, foi utilizada a entrevista semiestruturada, guiada por um roteiro previamente elaborado pelas pesquisadoras, contendo questões norteadoras de acordo com os objetivos do estudo. A entrevista foi composta pelos dados de identificação (sexo, idade, instituição de ensino), período de graduação profissional, tempo de atuação no Projeto de Extensão Sorriso de Plantão e por seis questões abertas consideradas importantes para a temática da pesquisa, sendo elas: 1 . O que você entende por multidisciplinaridade e interdisciplinaridade? De que modo esse tema é discutido na sua formação? 2 . Considerando o que você entende por interdisciplinaridade e interprofissionalidade, comente como estes são apresentados no transcorrer da sua graduação e da participação no Projeto de Extensão Sorriso de Plantão. 3. Como é a vivência com estudantes de outros cursos de graduação no Projeto de Extensão Sorriso de Plantão? Recorda-se de alguma experiência/momento que gostaria de relatar? 4. O que o trabalho interdisciplinar vivenciado no Projeto proporciona na sua formação profissional? 5. O que você considera como desafio da interdisciplinaridade durante a sua formação e participação no Projeto? 6. Deseja acrescentar algo que eu não perguntei? As entrevistas foram gravadas com a permissão dos participantes, sendo assinado o termo de autorização para gravação da voz.

O referencial teórico metodológico que subsidiou a análise dos dados foi a técnica de Análise de Conteúdo, na modalidade temática, de acordo com Bardin (2011). Todas as entrevistas foram transcritas na íntegra e, a partir disso, foi realizada a etapa de leitura flutuante. Depois, as falas foram codificadas e separadas por meio do processo de categorização. Esse processo de tratamento dos resultados permitiu a construção da interpretação das falas. Seguiram-se, portanto, as distintas fases da análise: pré-análise, exploração do material e tratamento dos resultados.

Para melhor entendimento e organização da apresentação dos resultados, e como forma de proteger a identificação dos participantes da pesquisa, foi utilizada a sigla "ES" seguida de número cardinal nas falas dos estudantes entrevistados.

\section{Resultados e Discussão}

Dos doze estudantes convidados, todos aceitaram participar do estudo, dez de IES pública e dois de IES privada. Os participantes, em sua maioria, são do sexo feminino e a média de idade foi de 22 anos, com mínimo de 20 anos e máximo de 24 anos. Quanto ao período de graduação profissional, o estudo revelou que o tempo médio de graduação é de 3 anos e 6 meses, e o tempo de atuação no Projeto de Extensão Sorriso de Plantão foi de cerca de dois anos. Na Tabela 1 está descrita a caracterização dos participantes da pesquisa.

Tabela 1 - Caracterização dos participantes da pesquisa.

\begin{tabular}{|c|c|c|c|c|c|c|}
\hline Participante & Sexo & Idade & $\begin{array}{l}\text { Curso de } \\
\text { Graduação }\end{array}$ & $\begin{array}{l}\text { Período da } \\
\text { graduação } \\
\text { profissional }\end{array}$ & $\begin{array}{c}\text { Tempo de atuação } \\
\text { no Projeto Sorriso } \\
\text { de Plantão }\end{array}$ & $\begin{array}{c}\text { Instituição de } \\
\text { Ensino }\end{array}$ \\
\hline ES1 & $\mathrm{F}$ & 24 & Medicina & $8^{\circ}$ & 2 anos & Privada \\
\hline ES2 & $\mathrm{F}$ & 22 & Fisioterapia & $7^{\circ}$ & 2 anos & Pública \\
\hline ES3 & $M$ & 20 & Terapia Ocupacional & $7^{\circ}$ & 2 anos & Pública \\
\hline ES4 & $\mathrm{F}$ & 23 & Fisioterapia & $9^{\circ}$ & 2 anos & Pública \\
\hline ES5 & $\mathrm{F}$ & 22 & Terapia Ocupacional & $5^{\circ}$ & 3 anos & Pública \\
\hline ES6 & M & 24 & Terapia Ocupacional & $5^{\circ}$ & 2 anos e 6 meses & Pública \\
\hline ES7 & $\mathrm{F}$ & 22 & Fisioterapia & $5^{\circ}$ & 3 anos & Pública \\
\hline ES8 & $\mathrm{F}$ & 21 & Enfermagem & $9^{\circ}$ & 3 anos & Pública \\
\hline ES9 & $\mathrm{F}$ & 23 & Medicina & $7^{\circ}$ & 2 anos e 6 meses & Pública \\
\hline ES10 & $\mathrm{F}$ & 22 & Odontologia & $6^{\circ}$ & 1 ano e 3 meses & Pública \\
\hline ES11 & M & 24 & Fisioterapia & $9^{\circ}$ & 2 anos & Pública \\
\hline ES12 & $\mathrm{F}$ & 20 & Fisioterapia & $10^{\circ}$ & 4 anos & Privada \\
\hline
\end{tabular}


As duas categorias temáticas que emergiram da análise das entrevistas foram: entendimento sobre interdisciplinaridade durante a formação profissional em saúde; e potencialidades e desafios do trabalho interdisciplinar: tarefa (im)possível? A seguir, serão apresentadas cada uma delas com suas possíveis inferências e interpretações.

\section{Entendimento sobre interdisciplinaridade durante a formação profissional em saúde}

No ponto de vista pedagógico, ao debater questões de natureza curricular, de ensino e aprendizagem acadêmica, a discussão sobre interdisciplinaridade abarca concepções diversas e complementares. Nesse sentido, ao serem indagados sobre o entendimento acerca do conceito de interdisciplinaridade e sua correlação prática, a interprofissionalidade, os participantes do estudo destacaram em suas falas:

"Eu entendo que seria as diversas profissóes, cada profissional com o seu conhecimento, mas atuando em conjunto, de forma integrada, visando um objetivo comum." (ESI)

"Assim, para entender os conceitos eu costumo muito desmembrar a palavra, sabe? Então "Inter" significa entre, entre as disciplinas. Já a interprofissionalidade remete à prática, sendo as várias profissões, vários saberes atuando juntos, com o mesmo propósito, um ajudando o outro em prol de um objetivo." (ES9)

"Eu entendo que a interprofissionalidade é o trabalho em equipe, com profissionais de diferentes áreas atuando juntos. Éo trabalho em conjunto, com objetivos em comum, que não necessariamente se tratam da especificidade de uma profissão, por exemplo, algo próprio da fisioterapia ou da Terapia Ocupacional, claro que cada um tem seu olhar, mas são olhares compartilhados e integrados."

(ES11)

Diante dos conceitos relatados, é possível perceber que os estudantes entrevistados conseguem compreender a interdisciplinaridade como a integração entre as disciplinas e os saberes, enquanto que a interprofissionalidade está mais relacionada com a integração das práticas profissionais em que se desenvolve o trabalho em equipe de saúde. As falas destacadas corroboram com o que é descrito por Farias et al. (2018), que salientam a necessidade de se fazer uma distinção entre interdisciplinaridade e interprofissionalidade, principalmente no contexto atual do setor saúde em que há um debate crescente acerca do trabalho interprofissional, destacando este como uma das melhores formas de se enfrentar as problemáticas altamente complexas do setor da saúde e a concretização da interdisciplinaridade.

Em contrapartida, apesar da distinção existente entre interdisciplinaridade e interprofissionalidade, é notório que os conceitos estão entrelaçados e que, na maioria das vezes, um perpassa o outro, a partir da união entre saberes e práticas. Japiassu (1976) destaca que a interdisciplinaridade compreende a intensidade das trocas entre os profissionais, a integração e a articulação de diferentes saberes e práticas que geram uma intervenção, uma ação comum.

O estudo indicou também que os estudantes entrevistados apontam para o equívoco de confundir qualquer trabalho em grupo com interdisciplinaridade. Nesse aspecto, os participantes conseguiram destacar a diferença entre o trabalho inter e multiprofissional, salientando que a multidisciplinaridade encontra-se hierarquicamente em nível inferior de integração entre os diversos saberes, quando comparada à interdisciplinaridade:

"(...) a multidisciplinaridade a gente, infelizmente, ainda vê muito mais sendo aplicada, porque são os profissionais atuando em um mesmo serviço, mas de forma separada. Na interdisciplinaridade há o compartilhamento de conhecimentos entre os profissionais, todos juntos em volta de um indivíduo, que precisa ser olhado de forma integrada." (ES6) 


\begin{abstract}
"(...) eu entendo que o trabalho multidisciplinar são vários profissionais atuando dentro da sua própria área, mas o trabalho interdisciplinar é quando esses profissionais trabalham de forma integrada, cada um contribui de uma forma, onde há compartilhamento, que afeta também o trabalho do outro, mas obtém um resultado muito melhor, muito mais completo do que cada um atuando de forma isolada, como na multi." (ES10)
\end{abstract}

É necessário refletir que a interdisciplinaridade representa uma nova consciência da realidade, um novo pensar, que resulta em um ato de troca, de reciprocidade e integração entre áreas distintas de conhecimento, visando à produção de novos saberes e a resolução de problemas de modo global e abrangente (Peleias et al., 2011). Ao percebermos que os estudantes entrevistados compreendem a diferença entre o trabalho multi e interprofissional, acreditamos que há mudanças reais nas formas de ver, pensar e fazer saúde, oriundas do processo de criação do SUS. Costa (2016) salienta que a interprofissionalidade complementa e fortalece os ideários do SUS e fornece subsídios para a construção de um projeto novo de sociedade a partir da concepção ampliada de saúde. Destacamos que o olhar para além do biológico, isto é, a necessidade de reconhecer os aspectos culturais, sociais, espirituais e econômicos na atuação em saúde junto à população, leva à busca pela interdisciplinaridade que, corroborando com Minayo (2010a), surge como uma estratégia inovadora para compreender, interpretar e explicar questões complexas, centradas, no caso do SUS, nos usuários do sistema, para os quais não bastam respostas de uma só área do conhecimento.

Poder et al. (2018) também ressaltam que uma das razões que orientam a implementação da interdisciplinaridade na saúde é a necessidade de gerenciar casos complexos que não podem ser resolvidos por um único especialista, destacando a importância do trabalho interprofissional para prestação do cuidado em saúde de forma eficiente e de qualidade.

Outro aspecto importante destacado por um dos participantes do estudo refere-se à dificuldade encontrada nos serviços de saúde quanto à compreensão e a ação por demais estudantes e profissionais da área da saúde acerca do trabalho interdisciplinar:

"Às vezes as pessoas trabalham de forma multi, achando que estão trabalhando de forma inter, por falta de conhecimento mesmo ou por não saber aplicar, não sei (...) por isso que é tão importante a teoria aliada à vivência prática durante a formação, pra que a gente consiga realmente trabalhar de acordo com a proposta da interdisciplinaridade". (ES5)

Nesse seguimento, em concordância com Scherer et al. (2013), percebemos que, por muitas vezes, a interdisciplinaridade é entendida quanto a sua importância na política de saúde, porém assumida erroneamente pelos profissionais, existindo lacunas entre o compreendido e o realizado. Dessa forma, salientamos que há um descompasso entre conhecimento e ação, ou seja, por vezes os profissionais, de fato, não possuem o conhecimento teórico-prático do trabalho interdisciplinar, ou às vezes até possuem o conhecimento teórico, mas no momento de agir existe a dificuldade de efetivar a cooperação e o trabalho integrado.

Nessa perspectiva, destacamos que essa realidade reflete o saber compartimentado e distante do sujeito social que, infelizmente, ainda se encontra presente desde o início da formação profissional em saúde. Porém, ressalta-se também que alguns dos processos formativos em curso encontram-se na busca pela criação de outro modo de pensar e agir, visando superar o individualismo oriundo de uma ótica fragmentadora e hegemônica. Dessa forma, torna-se uma incitação contínua incorporar na formação em saúde que "ninguém precisa ter medo de, num trabalho complexo e interdisciplinar, ficar engolido pelo grupo. Não há esse perigo, pois cada um está ali exatamente para dar sua contribuição e se enriquecer com a interfertilização de todos" (Minayo, 2010a). 
Assim, refletindo sobre a importância do conhecimento teórico acerca da interdisciplinaridade apreendido durante a formação profissional em saúde, os participantes da pesquisa foram indagados quanto aos espaços e/ou disciplinas que promoveram essa discussão nas universidades. Diante das falas dos entrevistados destacamos as disciplinas de Saúde Coletiva e Saúde e Sociedade como primordiais para construção desse conhecimento:

"Na disciplina de Saúde Coletiva já tinha ouvido falar, mas de forma mais teórica mesmo, até a diferença entre multi e inter, de forma básica. Eu ainda ficava pensando: como isso acontece na prática?" (ES6)

"Durante a graduação, eu ouvi falar sobre a interdisciplinaridade em uma disciplina que é Saúde e Sociedade, onde a gente estuda sobre a atuação na Atenção Básica (...) é aquela coisa, na disciplina o aprendizado fica mais voltado para teoria mesmo. "(ES9)

"Principalmente na disciplina de Saúde e Sociedade a gente costumava discutir sobre o trabalho interdisciplinar (...) o problema é que a vivência na graduação fica muito voltada para sala de aula, para a parte puramente teórica. A teoria por si só não é suficiente. Ás vezes na sala eu ficava pensando como isso aconteceria na prática mesmo, se era possível..." (ES11)

A partir das falas dos entrevistados, percebemos que os estudantes demonstram forte interesse pela prática interdisciplinar durante a formação em saúde. No entanto, também se faz necessário ressaltar a importância da apropriação do conhecimento teórico para construção de um novo perfil do profissional da saúde. Moraes \& Lopes (2009) destacam que as disciplinas de Saúde Coletiva e Saúde e Sociedade costumam aproximar os estudantes para a atenção primária à saúde, dando ênfase às funções generalistas e às competências para operacionalizar ações de prevenção de agravos e doenças e de promoção/educação em saúde. Tais aspectos implicam na formação de recursos humanos com perfil mais adequado às necessidades sociais dos usuários do SUS, propiciando aos estudantes a capacidade de aprender a aprender, de conhecer a importância de trabalhar em equipe, e de comunicar-se.

Por outro lado, reconhecemos que grande parte da formação em saúde ainda segue uma orientação biologicista, que concentra seus esforços na doença, no tratamento e nas ações de caráter médico, insuficientes para atender as exigências do novo momento sanitário. Como dito anteriormente, o modelo pedagógico de ensino em saúde ainda é muito mais voltado à multidisciplinaridade, com especialidades e procedimentos isolados, do que para a perspectiva interdisciplinar. Oelke et al. (2015) destacam que a integração entre os diversos profissionais é um componente fundamental para reforma do cuidado em saúde. Porém, na maioria dos serviços de saúde a assistência continua a ser muito fragmentada.

Por essa razão, refletindo sobre a importância de aliar o conhecimento teórico às práticas interdisciplinares durante a formação em saúde, destacamos as atividades extensionistas, de caráter interdisciplinar, como fundamentais para o enriquecimento da formação em saúde, tanto no nível teórico, quanto na perspectiva da interprofissionalidade. Corroborando com Fazenda (2011, p.11), acreditamos que "a interdisciplinaridade é essencialmente um processo que precisa ser vivido e exercido". Dessa forma, discutir sobre a prática interdisciplinar se torna indispensável para repensar a formação em saúde, entendendo que a interdisciplinaridade depende da atitude das pessoas frente ao conhecimento e como transformar essa atitude em fazeres.

Assim, apontamos que os estudantes entrevistados ressaltaram em suas falas a relevância da experiência do trabalho interdisciplinar oportunizada pelo Projeto de Extensão Sorriso de Plantão, durante a formação profissional em saúde: 
"O Sorriso de Plantão, além de possibilitar a participação e integração de estudantes de diversas áreas, ele trouxe uma discussão mais ampla da atuação de cada um, nas discussões dos casos clínicos, por exemplo". (ES4)

"Para vivenciar na prática mesmo como funciona o trabalho interdisciplinar é necessário um tempo maior de experiência e não somente ações pontuais. No Sorriso de Plantão a gente tem mais tempo de vivenciar na prática o que eu via na sala de aula, da atuação com estudantes de diversos cursos, que se unem em prol de uma atividade em comum, de um objetivo em comum". (ES8)

"A gente aprende durante as experiências no Projeto, na prática mesmo, que visões diferentes dentro de uma mesma situação são importantes, por exemplo, você com a visão da Terapia Ocupacional é diferente da minha visão de Medicina, de Fisioterapia, o trabalho é eficaz em equipe".

(ES9)

Logo, inferimos que a vivência prática no Projeto de Extensão Sorriso de Plantão favorece mudanças no perfil dos futuros profissionais da saúde, e possibilita uma formação de profissionais mais preparados para atuar em equipe e no mundo do trabalho, salientando a atuação interprofissional como primordial na produção do cuidado em saúde de forma integral, contínua e ampliada.

\section{Potencialidades e desafios do trabalho interdisciplinar: tarefa (im)possivel?}

Ao aceitar se esforçar fora do seu domínio próprio e da sua própria linguagem técnica, para aventurar-se em um domínio de que não é o proprietário exclusivo, o estudante se depara com inúmeras potencialidades e também desafios a serem enfrentados no cotidiano do trabalho interdisciplinar. Ao serem indagados quanto às potencialidades percebidas ao longo da experiência proporcionada no Projeto de Extensão Sorriso de Plantão, a troca de experiências entre os diferentes saberes ganha destaque entre os entrevistados:

"Nas conversas após os plantões, vão surgindo situações, casos de crianças com determinadas patologias, cada estudante vai tendo um olhar diferente sabe? Tipo a fisioterapia, como poderia ajudar? A medicina? (...) a gente vai interagindo e aprendendo". (ES1)

"Nos diálogos pós plantão a gente sempre interage, troca experiências, as vezes eu não entendo determinado termo técnico, aí o estudante de Medicina sabe e eu aprendo com ele. É uma troca. Não tem isso de um querer ser mais que o outro, cada um faz um pouquinho. Tem que ser assim nos serviços de saúde..." (ES2)

"Eu acredito que o trabalho interdisciplinar é uma troca muito rica (...) futuramente eu vou fazer parte de uma equipe de profissionais e hoje, dentro do Projeto, eu já tenho essa oportunidade de fazer parte de uma equipe que tem pessoas de diversas áreas e aí eu acabo conhecendo as particularidades de cada profissão e eles conhecem a minha também, o que podemos fazer juntos". (ES5)

Diante das falas dos estudantes, percebemos que a interdisciplinaridade pode começar com a troca e a mudança de conceitos como forma inicial básica de transpor fronteiras, conforme aponta Rosa (2007). Salientamos que, ao unir estudantes de diversos cursos da área da saúde, o Projeto de Extensão Sorriso de Plantão oportuniza o encontro propício para que as trocas de conhecimentos possam acontecer e que não existe uma 'receita' para se agir interdisciplinarmente, pois tudo irá depender dos agentes envolvidos e do grau de compromisso e responsabilidade com o trabalho desenvolvido.

Por outro lado, o trabalho interdisciplinar também provoca resistências, visto que promove a mudança de hábitos na busca por algo novo e, inicialmente, desconhecido (Meneses et al., 2019). Esse novo movimento gera desafios ao tentar romper com a cultura individualista na área da saúde, conforme é apontado pelos participantes do estudo: 
"Eu vejo muito médico se achando autoritário, superior (...) é um desafio lidar com profissionais individualistas, dentro do Projeto eu aprendi que o trabalho em equipe é essencial e só de forma interdisciplinar a gente consegue resultados completos" (ES1)

"É um desafio lidar com um profissional que não quer se abrir para o dialogo, de ser tipo 'é isso e acabou', de não querer ouvir o outro (...) A cultura individualista ainda é muito grande na área da saúde, 'eu sou o melhor e não preciso do outro' ou 'eu já sei disso, não vou me interessar pelo saber do outro'"(ES2)

"É muito mais fácil você fazer 'só o seu trabalho', por exemplo, o médico sentar e passar uma medicação para o paciente, mas ele sentar com outros profissionais e discutir como todos juntos podem atuar para um cuidado integral... esse é o desafio".

(ES3)

É necessário refletir que superar o individualismo na área da saúde é entender que as necessidades dos usuários não se reduzem àquelas apreensíveis por uma única categoria profissional (Gonze \& Silva, 2011). Trata-se de um desafio saber ouvir e aceitar o conhecimento diferente do outro, uma vez que é mais cômodo buscar apoio entre os seus iguais. Nesse sentido, ao lidar com esse desafio, o Projeto de Extensão Sorriso de Plantão também busca em suas atividades instigar aos estudantes o conhecimento sobre os papéis de cada profissão, com o intuito de ultrapassar o individualismo, além de estimular o respeito mútuo entre as diferentes categorias profissionais:

"Saber lidar com os diferentes saberes dentro da equipe é desafiador (...) É preciso entender que o saber e o papel do outro não vai menosprezar a minha formação, pelo contrário, mostra que o ser humano é complexo e eu sozinha não dou conta".

(ES1)

"Cada profissão tem sua especificidade, seu papel e a gente precisa trabalhar junto, conhecendo os limites. Se o médico, por exemplo, conhece o papel do fisioterapeuta, do terapeuta ocupacional, do fonoaudiólogo... ele não vai prescrever condutas, vai buscar estabelecer diálogo entre os profissionais. Isso é respeito!" (ES2)

Para Minayo (2010a), a interdisciplinaridade nos despoja da vaidade unidisciplinar, mas potencializa quem dialoga e contribui para abrir seus horizontes. Nesse aspecto, refletimos que o trabalho interdisciplinar emerge da coletividade, na qual prevalece a integração entre todos os profissionais envolvidos, promovendo na equipe de saúde um olhar mais integral para o usuário. O estudante, como futuro profissional, que busca orientar suas práticas seguindo a abordagem interdisciplinar, certamente será guiado pelo princípio da integralidade, buscando escapar dos reducionismos. O despertar para a importância da integralidade do cuidado em saúde também foi um fator mencionado pelos participantes do estudo como uma das potencialidades do trabalho interdisciplinar apreendida no decorrer da experiência no Projeto de Extensão Sorriso de Plantão:

"Eu aprendi no Sorriso de Plantão que trabalhando de forma interdisciplinar eu consigo enxergar o paciente para além da fisioterapia, da parte motora, respiratória... eu vejo ele como um todo. O estado de saúde do usuário, o fato dele tá doente, depende de um contexto muito amplo, que precisa ter um olhar completo dos diversos profissionais". (ES4)

"No Projeto a gente aprende que é necessário ir além da visão clínica do paciente, sabe? A gente começa a perceber a importância do trabalho em equipe e de como cada um pode ajudar enquanto grupo de estudantes que futuramente serão profissionais. É um olhar integral do usuário que eu só consigo enxergar através da interdisciplinaridade". (ES7)

"Eu acredito que enquanto futuros profissionais da saúde a gente precisa enxergar para além da especificidade. É necessário ter diálogo, trabalhar em equipe... no meu ver o trabalho só é integral e eficaz a partir de múltiplos olhares compartilhados". (ES12) 
A partir das falas dos entrevistados, percebemos que a prática interdisciplinar durante a formação profissional promove uma dimensão ampliada da integralidade do cuidado em saúde, proporcionando aos estudantes o desenvolvimento de competências importantes para superar a fragmentação do processo de trabalho em saúde, estreitando as relações entre os diferentes saberes. Nesse seguimento, apontamos a escuta entre os profissionais como um dos fatores imprescindíveis para melhorar a interação nas equipes e qualificá-las.

A mudança do processo de trabalho em saúde só é possível se houver a compreensão de cada trabalhador sobre o modo de produzir saúde e de aderir à nova forma de agir na relação com o usuário (Esmeraldo et al., 2009). Assim, para que os profissionais possam trabalhar de forma interdisciplinar com a perspectiva de promover um cuidado integral para o usuário, é necessário primeiramente estabelecer uma escuta qualificada entre a equipe de saúde, para que assim os usuários possam ser igualmente ouvidos na sua integralidade.

Com relação à importância da escuta entre os profissionais de saúde, os participantes do estudo expuseram em suas falas o quanto essa competência é trabalhada no Projeto de Extensão Sorriso de Plantão, e refletiram:

"Eu acho que a experiência no Projeto me fez aprender a ouvir com atenção e considerar as colocações dos demais profissionais. De procurar compreender e respeitar a visão de cada um, dentro da sua perspectiva. Eu aprendi que a gente precisa ser equipe e não EUquipe". (ES4)

"Como vou escutar bem o usuário, se eu não sei nem escutar o meu colega de trabalho? Eu não aplico a interdisciplinaridade se eu só pensar em mim e não deixar que os demais se expressem. $A$ experiência interdisciplinar me faz ter uma escuta mais qualificada". (ES11)

No processo de escutar o outro, ao se assumir a provocação de pôr as próprias certezas entre quatro paredes e passar a acolher o ponto de vista da equipe de saúde ou do próprio usuário, amplia-se a capacidade de antever outras dimensões possíveis (Raimundo \& Cadete, 2012). Os autores salientam ainda que a escuta qualificada é uma competência que não se pode dispensar, e que deveria ser ensinada e exercitada na graduação dos cursos da área da saúde, sendo indispensável para uma formação interdisciplinar.

Nesse ponto de vista, o estudo revelou que, apesar dos inúmeros desafios enfrentados no exercício da interdisciplinaridade, as potencialidades descritas pelos estudantes entrevistados propuseram que a prática interdisciplinar fortalece a formação profissional, com base nos saberes integrados, articulados e atualizados, permitindo a abertura de novos campos do conhecimento e de novas descobertas, que possibilitem uma melhor vivência do trabalho em saúde.

Assim, acreditamos que a interdisciplinaridade não só é possível como também é um requisito fundamental para concretização do tão almejado cuidado integral em saúde, que, corroborando com Fazenda (2014), depende de atitude, de uma mudança de postura em relação ao conhecimento, e da substituição da concepção fragmentária para a unidade do ser humano.

"No Sorriso de Plantão eu comecei a entender que o trabalho interdisciplinar é possivel e do quanto essa proposta inovadora pode transformar a assistência em saúde (...) Se a equipe não trabalha de forma harmoniosa e integrada, não tem como ter uma relação integral com o usuário, ele é o ponto chave do nosso trabalho e se não há esse compartilhamento entre os profissionais dificilmente o usuário será assistido na sua integralidade". (ES11)

\section{Considerações Finais}

Este estudo revelou que a interdisciplinaridade sobrevive do desejo de transformação. Acreditamos que a mudança de paradigma se dá especialmente no ensino superior, visto que é nele que o tripé ensino, pesquisa e extensão influem consideravelmente no contexto social atual. 
Analisando as percepções dos estudantes integrantes do Projeto de Extensão Sorriso de Plantão, foi possível perceber que as atividades extensionistas na formação profissional podem superar visões mecanicistas e fragmentadoras do cuidado em saúde, dando lugar a uma formação holística, capaz de gerar novas respostas às demandas contemporâneas, ampliando o potencial de cada futuro profissional e as possibilidades dos coletivos trabalharem interdisciplinarmente.

A pesquisa evidenciou a necessidade de apostarmos na integração entre teoria e prática, entendendo o diálogo e as trocas de conhecimentos entre os diferentes saberes como elementos essenciais para o trabalho interdisciplinar e, consequentemente, para alcançar maior resolutividade nas ações de saúde, promovendo a integralidade do cuidado.

Nessa perspectiva, em um contexto marcado por transformações do conhecimento cada vez mais rápidas e profundas, conclui-se que é premente a necessidade da ampliação e desenvolvimento de práticas interdisciplinares na formação profissional em saúde, compreendendo que a percepção do coletivo possibilita ações críticas e integradas, implicando em um posicionamento ético e político que necessita ser despertado, orientado e discutido desde o início da formação.

\section{Contribuição de cada autor}

D.C.S. contribuiu com a produção dos dados, análise e interpretação dos resultados e elaboração do artigo até a sua versão final. M.R.S. contribuiu na concepção do trabalho, orientação, análise e interpretação dos resultados e revisão crítica do artigo e aprovação final da versão a ser publicada.

\section{Referências}

Bardin, L. (2011). Análise de Conteúdo. São Paulo: Edições 70.

Bazzo, R. P. (2012). Interdisciplinaridade no ensino de graduação na área da saúde: Percepção de estudantes. (Trabalho de Conclusão do Curso). Centro de Ciências da Saúde, Universidade Federal de Santa Catarina, Florianópolis, Brasil. Recuperado de: https://repositorio.ufsc.br/xmlui/handle/123456789/103651

Costa, M. V. (2016). A educação interprofissional no contexto brasileiro: Algumas reflexões. Revista Interface, Comunicação, Saúde e Educação, 20(5), 197-198.

Del-Masso, M. C. S., Roveda, J. A. F., Zuanon, A. C. C., \& Galhardo, E. (2017). Interdisciplinaridade em Extensão Universitária. Revista Ciência em Extensão, 13(3), 2-12.

Esmeraldo, G. R. D. O. V., de Oliveira, L. C., de Souza, K. M. M., Araújo, M. Â. M. M., Esmeraldo Filho, C. E., \& de Noronha Viana, É. M. (2009). Análise do acolhimento na estratégia de saúde da família sob a perspectiva do usuário. Revista de APS - Atenção Primária à Saúde, 12(2), 119-130.

Farias, D. N. D., Ribeiro, K. S. Q. S., Anjos, U. U. D., \& Brito, G. E. G. D. (2018). Interdisciplinaridade e interprofissionalidade na Estratégia Saúde da Família. Trabalho, Educação e Saúde, 16(1), 141-162.

Fazenda, I. C. A. (2008). Interdisciplinaridade: História, teoria e pesquisa. 15a ed. São Paulo: Papirus.

Fazenda, I. C. A. (2011). Integração e interdisciplinaridade no ensino brasileiro: Efetividade ou ideologia. 6a ed. São Paulo: Loyola.

Fazenda, I. C. A. (2014). Interdisciplinaridade: Pensar, pesquisar e intervir. São Paulo: Cortez.

Gattas, M. L. B. (2005). Interdisciplinaridade em cursos de graduação na área da saúde da Universidade de UberabaUNUIBE. (Tese de Doutorado). Escola de Enfermagem de Ribeirão Preto, Universidade de São Paulo, Ribeirão Preto, Brasil. Recuperado de http://www.teses.usp.br/teses/disponiveis/22/22131/tde-20062005-083314/pt-br.php

González, A. D., \& Almeida, M. J. (2010). Integralidade da saúde: Norteando mudanças na graduação dos novos profissionais. Revista Ciência \& Saúde Coletiva, 15(3), 757- 760. 
Gonze, G. G., \& Silva, G. A. D. (2011). A integralidade na formação dos profissionais de saúde: Tecendo valores. Physis: Revista de Saúde Coletiva, 21(1), 129-146.

Japiassu, H. (1976). Interdisciplinaridade e patologia do saber. Rio de Janeiro: Imago.

Meneses, A. D. F. P., Campos, P. P. T. V. Z., Gemma, S. F. B., \& Fuentes-Rojas, M. (2019). Seminários interdisciplinares como instrumento de articulação de saberes: um relato de experiência. Revista Eletrônica de Educação, 13(1), 336-349.

Minayo, M. C. S. (2010a). Disciplinaridade, interdisciplinaridade e complexidade. Revista Emancipação, 10(2), 435-442.

Minayo, M. C. S. (2010b). Pesquisa Social. Teoria, método e criatividade. 29ạ ed. Petrópolis: Vozes.

Moraes, J. T., \& Lopes, E. M. T. (2010). A formação de profissionais de saúde em instituições de ensino superior de Divinópolis, Minas Gerais. Revista Trabalho, Educação e Saúde, 7(3), 435-444.

Oelke, N. D., Suter, E., da Silva Lima, M. A. D., \& Van Vliet-Brown, C. (2015). Indicators and measurement tools for health system integration: a knowledge synthesis protocol. Systematic Reviews, 4(1), 99.

Oliveira, F., \& Goulart, P. M. (2015). Fases e faces da extensão universitária: Rotas e concepções. Revista Ciência e Extensão, 11(3), 8-27.

Peleias, I. R., Mendonça, J. D. F., Slomski, V. G., \& Fazenda, I. C. A. (2011). Interdisciplinaridade no ensino superior: análise da percepção de professores de controladoria em cursos de ciências contábeis na cidade de São Paulo. Avaliação: Revista da Avaliação da Educação Superior (Campinas), 16(3), 499-532.

Poder, T. G., Carrier, N., \& Bédard, S. K. (2018). Measuring interdisciplinarity in clinical practice with IPC59, a modified and improved version of IPC65. Plos One, 13(7), e0197484.

Raimundo, J. S., \& Cadete, M. M. M. (2012). Escuta qualificada e gestão social entre os profissionais de saúde. Acta Paulista de Enfermagem, 25(2), 61-67.

Rosa, M. G. O. (2007). A interdisciplinaridade e as novas formas de organização do conhecimento. Revista AprenderCaderno de Filosofia e Psicologia da Educação, 8, 101-112.

Scherer, M. D. A., Pires, D. E. P., \& Jean, R. A. (2013). Construção da interdisciplinaridade no trabalho da Equipe de Saúde da Família. Revista Ciência \& Saúde Coletiva, 18(11), 3203-3212.

Como citar este artigo:

Santana, D. de C., \& Silva, M. R. da. A percepção de estudantes da área da saúde sobre o trabalho interdisciplinar: experiência no projeto de extensão Sorriso de Plantão. Revista Brasileira de Extensão Universitária, 11(1), 13-24. https://periodicos.uffs.edu.br/index.php/RBEU/article/view/10753/pdf 